Open Access

Original Article

\title{
Effect of wearing cotton towel Ihram and plain Ihram on lung function among Hajj Pilgrims
}

\author{
Sultan Ayoub Meo', Muhammad Iqbal', Adnan Mahmood Usmani ${ }^{3}$, \\ Abdulrahman Abdulaziz Almana ${ }^{4}$, Abdulrahman Hamad Alrashed ${ }^{5}$, \\ Khalid Abdullah Al-Regaiey ${ }^{6}$
}

\begin{abstract}
Objectives: Hajj is the world's largest gathering to Makkah, Saudi Arabia. Wearing cotton made Ihram is a basic and an essential component of Hajj. The aim of this study was to investigate the lung functions among Hajj pilgrims who were wearing cotton towel ihram (ihram with fibers) compared to those who were wearing plain cotton ihram (ihram without fibers).

Methods: Ninety male, non-smoker, Hajj pilgrim volunteers with age ranged 20-60 years were selected. Forty five of them wore cotton towel ihram and 45 wore plain ihram. A day before leaving for Hajj and wearing ihram $\left(6^{\text {th }}\right.$ Dhu-al-Hijjah) lung function base line parameters of Hajj pilgrims were determined. Hajj Pilgrims continuously wear ihram from 7-10 th Dhu-al-Hijjah. In the afternoon of $10^{\text {th }}$ Dhu-al-Hijjah, after removal of ihram, all parameters were repeated and at the completion of Hajj when all pilgrims return to their homes at Riyadh, all parameters were recorded again.

Results: Before wearing Ihram, anthropometric and lung function baseline parameters were recorded, no significant difference was found between the study population. After wearing Ihram on the $7^{\text {th }}$ Dhu-alHijjah and its removal on the $10^{\text {th }}$ Dhu-al-Hijjah significant decline in the lung function test parameters was observed among Hajj pilgrims who were wearing cotton towel ihram. Forced Vital Capacity (FVC) $4.30 \pm 1.18$ vs. $5.03 \pm 1.41$ ( $p=0.01$ ); Forced Expiratory Flow $25 \%$ (FEF-25\%) $4.39 \pm 1.94$ vs. $5.69 \pm 2.84$ ( $p=0.03$ ); Forced Expiratory Flow-50\% (FEF-50\%) $2.93 \pm 1.65$ vs. $4.07 \pm 2.08(\mathrm{p}=0.01$ ); Forced Expiratory Flow-75\% (FEF$75 \%) 1.02 \pm 0.70$ vs. $1.66 \pm 0.94(\mathrm{p}=0.002)$ compared to those who were wearing plain ihram.

Conclusions: Lung function test parameters were decreased among the Hajj pilgrims who were wearing cotton towel ihram compared to those who were wearing plain cotton ihram. The pattern of impairment of lung function shows an obstructive peripheral airway lung involvement. It is suggested to conduct further large sample size studies to confirm the present study observations and reach at better conclusions.
\end{abstract}

KEYWORDS: Cotton Ihram, Hajj Pilgrims, Lung Function, Plain Ihram.

doi: https://doi.org/10.12669/pjms.35.4.727

How to cite this:

Meo SA, Iqbal M, Usmani AM, Almana AA, Alrashed AH, Al-Regaiey KA. Effect of wearing cotton towel Ihram and plain Ihram on lung function among Hajj Pilgrims. Pak J Med Sci. 2019;35(4):893-898. doi: https://doi.org/10.12669/pjms.35.4.727

This is an Open Access article distributed under the terms of the Creative Commons Attribution License (http://creativecommons.org/licenses/by/3.0), which permits unrestricted use, distribution, and reproduction in any medium, provided the original work is properly cited.

Correspondence:

Prof. Sultan Ayoub Meo, MBBS, PhD

Department of Physiology,

College of Medicine,

King Saud University,

Riyadh, Saudi Arabia.

Email: sultanmeo@hotmail.com

* Received for Publication: March 14, 2019

* $1^{\text {st }}$ Revision Received:

* $2^{\text {nd }}$ Revision Received:

* Final Revision Accepted: *
April 20, 2019

May 4, 2019

May 30, 2019

\section{INTRODUCTION}

Hajj is a unique Islamic ritual where each year about 2.5 million Muslims from all over the world travel to Makkah, Saudi Arabia to perform Hajj during the period 8-12 ${ }^{\text {th }}$ Dhu-al-Hijjah (Lunar month). ${ }^{1}$ Wearing Ihram is a basic and obligatory component for all male Hajj pilgrims. They continuously wear the ihram since the early morning of $8^{\text {th }}$ Dhu-al-Hijjah and remove it at the afternoon of $10^{\text {th }}$ Dhu-al-Hijjah; and remaining days 
from $10^{\text {th }}$ to $12^{\text {th }}$ Dhu-al-Hijjah, all Hajj pilgrims perform their remaining Hajj rituals without ihram but must stay in similar environment at Mina (a place at Makkah). Majority of the pilgrims tend to wear cotton towel ihram [Ihram with fibers], which contains cotton fibers (Fig.1A) which are released into the environment and may become a cause of respiratory complaints. Cotton fibers elicit proinflammatory mediators, which are involved in acute or chronic respiratory inflammation. ${ }^{2}$

The respiratory system is the most vulnerable body system for air pollution. Exposure to airborne cotton fiber and associated dust pollutants impairs the various physiological functions, represents a major factor promoting respiratory illness expression, and develops adverse effects on the human health. The respiratory problems are commonly seen during Hajj season. ${ }^{3}$ The hypothesis behind this study is that there are multiple factors, which can impair the respiratory health of Hajj pilgrims. However, we believe that, wearing cotton Ihram with fibers (Fig.1A) is one of the leading factors as it generates and upsurges the respiratory complaints in Hajj pilgrims. The aim of this study was to investigate the lung functions among Hajj pilgrims who were wearing cotton towel ihram (ihram with fibers) compared to those who were wearing plain cotton ihram (ihram without fibers).

\section{METHODS}

Initially we recruited 160 male hajj pilgrims, but after clinical history, we recruited 90 male hajj pilgrims for the research project. For individuals, serial number was allotted for wearing cotton or plain ihram, and adjustments were made in buses for travelling to Makkah, as well as staying in tents at Mina at Makkah city, for research procedure. A day before leaving for a Hajj and wearing ihram on $5^{\text {th }}$ Dhu-al-Hijjah, all the participants were gathered to obtain their base line lung function parameters. On the evening of $6^{\text {th }}$ Dhu-al-Hijjah both groups travelled for Makkah city to perform the Hajj rituals. Forty-five of them dressed up in cotton towel ihram and 45 were in plain ihram. Hajj pilgrims who wore cotton towel ihram were allowed to sit in one bus, and who wore plain ihram were allowed to sit in another bus. On arrival in Makkah city, hajj pilgrims who wore cotton towel ihram were allowed to join one tent for their stay in Mina, a place where all the pilgrims gathered to perform the various rituals of Hajj. Hajj pilgrims who wore plain towel ihram were allowed to join another tent for their stay in Mina and were instructed not to mix-up.

After the removal of Ihram, on the afternoon of $10^{\text {th }}$ Dhu-al-Hajj all the lung function parameters were again obtained. Following completion of all Hajj rituals on the evening of $12^{\text {th }}$ Dhu-al-Hijjah, both groups were advised to sit in the allocated buses to return back to Riyadh. On the $15^{\text {th }}$ Dhual-Hijjah, both groups were invited and all the parameters were re-investigated as before.

Exclusion Criteria: Initially 160 subjects who submitted their applications for hajj were interviewed, and clinical history and physical examinations were conducted. Subjects with any acute or chronic respiratory diseases, anemia, diabetes mellitus, malignancy, and also those who were current or former traditional cigarette smokers, shisha smokers and other tobacco product users were excluded from the study. Subjects who worked in any industry, which generates dust or fumes, were also excluded from the study. ${ }^{4,5}$

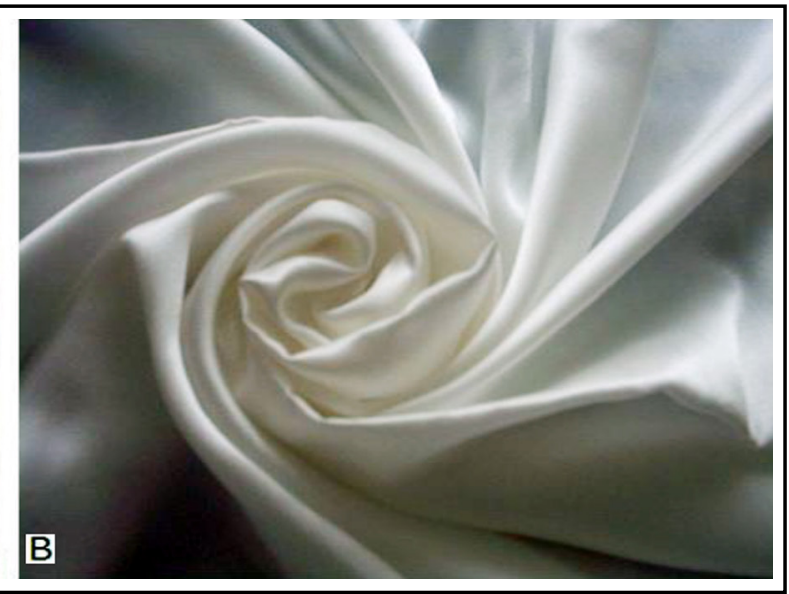

Fig.1: [A] Cotton towel ihram with fibers, [B] Plain cotton ihram without fibers. 
Spirometry: Spirometry was conducted using SPIROVIT SP-1 (Schiller, Switzerland) to assess lung function test parameters including "Forced Vital Capacity (FVC), Forced Expiratory Volume in First Second $\left(\mathrm{FEV}_{1}\right)$, Forced Expiratory Ratio $\left(\mathrm{FEV}_{1} / \mathrm{FVC} \%\right)$, Peak Expiratory Flow (PEF), Forced Expiratory Flow-25\% $\left(\mathrm{FEF}_{25 \%}\right)$; Forced Expiratory Flow-50\% $\left(\mathrm{FEF}_{50 \%}\right)$; and Forced Expiratory Flow- $75 \%\left(\mathrm{FEF}_{75 \%}\right)^{\prime \prime}$. The lung function test parameters were performed based on the official statement of the American Thoracic Society of Standardization 2005. ${ }^{6}$ Participants were given detailed descriptions of the tests. The tests were performed in the standing position with a nose clip at a fxed time of the day to minimize the diurnal variations. Separate new sterile mouth pieces for each individual were used to prevent any cross infections.

Ethical Statement: The study was approved by "Institutional Review Board, Ethics Committee, College of Medicine Research Centre, King Saud University, Riyadh, Saudi Arabia (E-14-1245)".

Statistical Analysis: The results were analyzed by using the Statistical Package for Social Sciences (SPSS) version 20.0 for Windows. Student's t-test was applied to test the difference of the means between the two quantitative variables. The level of significance was assumed at $\mathrm{p}<0.05$.

\section{RESULTS}

The physiological variables, age, height, weight were matched between the Hajj pilgrims who were wearing cotton towel ihram compared to those who were wearing plain cotton ihram (Table-I). The mean age of Hajj pilgrims who were wearing cotton towel ihram group was $36.08 \pm 10.94$ vs those who were wearing plain cotton ihram 37.22 \pm 9.41 ; height $1.64 \pm 0.70$ vs $164.0 \pm 05$; weight $72.69 \pm 13.27$ vs $71.53 \pm 8.94$ (Table-I). There was no significant difference in anthropometric variable between the groups (Table-I).

Table-I: Comparison of anthropometric parameters between Hajj pilgrims wearing cotton towel Ihram compared to Hajj pilgrims wearing plain Ihram (Pre Hajj data).

\begin{tabular}{lccc}
\hline Parameters & $\begin{array}{c}\text { Towel Ihram } \\
\text { Group }(n=45)\end{array}$ & $\begin{array}{c}\text { Plain Ihram } \\
\text { Group }(n=45)\end{array}$ & P-Values \\
\hline Age (years) & $36.08 \pm 10.94$ & $37.22 \pm 9.41$ & 0.630 \\
Height $(\mathrm{m})$ & $1.64 \pm .07$ & $1.64 \pm 0.05$ & 0.706 \\
Weight $(\mathrm{kg})$ & $72.69 \pm 13.27$ & $71.53 \pm 8.94$ & 0.660 \\
\hline
\end{tabular}

Vales are presented in Mean \pm SEM.
A day before leaving for Hajj and wearing the required Ihram, baseline lung function test parameters were recorded. There was no significant difference in the lung function test parameters among hajj pilgrims wearing cotton towel ihram compared to those who were wearing plain cotton ihram (Table-II). Forced Vital Capacity $(4.49 \pm 1.53$ vs. $4.57 \pm 1.28)$; Forced Expiratory Volume in First Second (2.99 \pm 0.61 vs. 3.01 \pm 0.63$)$; Forced Expiratory Ratio (71.17 \pm 18.11 vs. $67.12 \pm 15.67)$; Peak Expiratory Flow (5.54 \pm 2.05 vs. $5.05 \pm 2.25$ ); Forced Expiratory Flow-25\% (5.10 \pm 1.89 vs. $4.82 \pm 2.27)$; Forced Expiratory Flow-50\% (3.21 \pm 1.59 vs. $3.12 \pm 1.94)$; Forced Expiratory Flow-75\% (1.29 \pm 0.87 vs. $1.13 \pm 0.86$ ) between the Hajj pilgrims who were wearing cotton towel ihram compared to those who were wearing plain cotton ihram (Table-II).

The lung function test parameters were recorded during Hajj on $10^{\text {th }}$ of Dhu-al-Hajj, after the removal of the Ihram. There was a significant decline in the lung function test parameters among Hajj pilgrims who were wearing cotton towel ihrams. Forced Vital Capacity (FVC) $4.30 \pm 1.18$ vs. $5.03 \pm 1.41$ $(\mathrm{p}=0.01)$; Forced Expiratory Flow-25\% (FEF-25\%) $4.39 \pm 1.94$ vs. $5.69 \pm 2.84$ ( $\mathrm{p}=0.03$ ); Forced Expiratory Flow $-50 \%$ (FEF $50 \%$ ) $2.93 \pm 1.65$ vs. $4.07 \pm 2.08$ $(\mathrm{p}=0.01)$; Forced Expiratory Flow-75\% (FEF-75\%) $1.02 \pm 0.70$ vs. $1.66 \pm 0.94 \quad(p=0.002)$ compared to those who were wearing plain ihram (Table-III). However, there was no significant difference in Forced Expiratory Volume in First Second (FEV1) $2.89 \pm 0.75$ vs. $3.56 \pm 1.09$ ( $\mathrm{p}=0.386$ ); Forced Expiratory Ratio (FEV1/FVC Ratio) 68.59 \pm 13.12 vs. $71.14 \pm 13.08(\mathrm{p}=0.543)$ and Peak Expiratory Flow (PEF) $5.15 \pm 1.9$ vs. $6.07 \pm 2.74 \quad(p=0.127)$ between

\section{Table-II: Comparison of lung function parameters between Hajj pilgrims wearing Cotton Towel Ihram compared to Hajj pilgrims wearing Plain Ihram (Pre Hajj data).}

\begin{tabular}{lccc}
\hline Parameters & $\begin{array}{c}\text { Cotton Towel } \\
\text { Ihram } \\
\text { Group }(n=45)\end{array}$ & $\begin{array}{c}\text { Plain Ihram } \\
\text { Group }(n=45)\end{array}$ & P Values \\
\hline FVC (lit) & $4.49 \pm 1.53$ & $4.57 \pm 1.28$ & 0.827 \\
FEV1 (lit/sec) & $2.99 \pm .61$ & $3.01 \pm 0.63$ & 0.912 \\
FEV//FVC & $71.17 \pm 18.11$ & $67.12 \pm 15.67$ & 0.305 \\
Ratio (\%) & & & \\
PEF (lit/ sec) & $5.54 \pm 2.05$ & $5.05 \pm 2.25$ & 0.317 \\
FEF-25\% (lit/sec) & $5.10 \pm 1.89$ & $4.82 \pm 2.27$ & 0.549 \\
FEF-50\% (lit/sec) & $3.21 \pm 1.59$ & $3.12 \pm 1.94$ & 0.824 \\
FEF-75\% (lit/sec) & $1.29 \pm .875$ & $1.13 \pm 0.86$ & 0.430 \\
\hline
\end{tabular}

Vales are presented in Mean \pm SEM, NS: Non-Significant. 
Table-III: Comparison of lung function parameters between Hajj pilgrims wearing Cotton Towel Ihram compared to Hajj pilgrims wearing Plain Ihram (During Hajj data).

\begin{tabular}{lccc}
\hline Parameters & $\begin{array}{c}\text { Towel Ihram } \\
\text { Group }(n=45)\end{array}$ & $\begin{array}{c}\text { Plain Ihram } \\
\text { Group }(n=45)\end{array}$ & P Values \\
\hline FVC (lit) & $4.30 \pm 1.18$ & $5.03 \pm 1.41$ & 0.018 \\
FEV1 (lit/sec) & $2.89 \pm .755$ & $3.56 \pm 1.09$ & 0.386 \\
FEV//FVC & $68.59 \pm 13.12$ & $71.14 \pm 13.08$ & 0.543 \\
Ratio (\%) & & & \\
PEF (lit/ sec) & $5.15 \pm 1.99$ & $6.07 \pm 2.74$ & 0.127 \\
FEF-25\% (lit/sec) & $4.39 \pm 1.94$ & $5.69 \pm 2.84$ & 0.031 \\
FEF-50\% (lit/sec) & $2.93 \pm 1.65$ & $4.07 \pm 2.08$ & 0.013 \\
FEF-75\% (lit/sec) & $1.02 \pm .70$ & $1.66 \pm 0.94$ & 0.002 \\
\hline
\end{tabular}

Vales are presented in Mean \pm SEM; NS= Non-Significant.

the Hajj pilgrims who were wearing cotton towel ihram compared to those who were wearing plain cotton ihram (Table-III).

The lung function test parameters were also recorded after Hajj, and a significant decline was found among Hajj pilgrims who were wearing cotton towel ihrams in Peak Expiratory Flow (PEF) $5.69 \pm 1.87$ vs. $6.78 \pm 2.08$ ( $\mathrm{p}=0.015)$; Forced Expiratory Flow $25 \% \quad$ (FEF-25\%) $4.97 \pm 1.97$ vs. $6.30 \pm 2.08$ $(p=0.005)$ compared to those who were wearing plain cotton ihram (Table-IV).

\section{DISCUSSION}

This is the first novel study which presents an assessment of lung function parameters among Hajj pilgrims. A significant decline in the lung function test parameters was found among Hajj pilgrims who were wearing cotton towel ihrams compared to those who were wearing plain ihrams. These parameters show some evidence that after Hajj, the lung function parameters of pilgrims wearing cotton towel ihrams decreased and this decline shows a peripheral obstructive airway lung impairment. However, these parameters were reversed a few days after the removal of the Ihram.

Hajj is one of the world's largest annual mass gathering on the planet. Approximately 2.5 million people from all over the world assemble annually at Makkah, Saudi Arabia to perform Hajj. ${ }^{7}$ Shakir et $\mathrm{al}^{8}{ }^{8}$ found that during Hajj, the most frequent complaints were related to respiratory problems. There are many factors promoting the respiratory diseases which include dust, air pollution ${ }^{9}$ and viral infections. ${ }^{10}$ Wearing cotton towel ihram with fibers increases the chances of releasing cotton fibers
Table-IV: Comparison of lung function parameters between Hajj pilgrims wearing Cotton Towel Ihram compared to Hajj pilgrims wearing Plain Ihram (After Hajj data).

\begin{tabular}{lccc}
\hline Parameters & $\begin{array}{c}\text { Towel Ihram } \\
\text { Group }(n=45)\end{array}$ & $\begin{array}{c}\text { Plain Ihram } \\
\text { Group }(n=45)\end{array}$ & P-Values \\
\hline FVC (lit) & $4.32 \pm .95$ & $4.56 \pm 1.01$ & 0.314 \\
FEV1 (lit/sec) & $2.80 \pm .90$ & $3.03 \pm 0.93$ & 0.060 \\
FEV//FVC & $70.45 \pm 16.00$ & $72.31 \pm 14.11$ & 0.465 \\
Ratio (\%) & & & \\
PEF (lit/ sec) & $5.69 \pm 1.87$ & $6.78 \pm 2.08$ & 0.015 \\
FEF-25\% (lit/sec) & $4.97 \pm 1.97$ & $6.30 \pm 2.08$ & 0.005 \\
FEF-50\% (lit/sec) $3.01 \pm 1.42$ & $3.55 \pm 1.85$ & 0.134 \\
FEF-75\% (lit/sec) & $1.18 \pm .85$ & $31.19 \pm 175.60$ & 0.301 \\
\hline
\end{tabular}

Vales are presented in Mean \pm SEM; NS= Non-Significant.

into the environment and may become a cause of respiratory complaints.

Environmental pollution enhances the global burden of allergic and respiratory diseases, including chronic obstructive pulmonary disease (COPD), asthma, pneumonia, and other respiratory problems. The links between environmental pollution and respiratory disease are multifaceted and current studies have showed an increased significance of air pollution associated respiratory problems. ${ }^{11}$ Exposure to environmental pollutants leads to respiratory diseases and other long-lasting health problems. ${ }^{12}$ A quarter of the diseases faced by mankind today occur due to exposure to dust, fumes and fibers in the environment.

Dangi and Bhise ${ }^{13}$ conducted a study among age and gender-matched male cotton mill workers working in weaving and spinning areas. These cotton mill workers showed a significant decrease in "Forced Expiratory Volume in First Second, Forced Expiratory Ratio (FEV1 / FVC Ratio) and Peak Expiratory Flow".

Paudyal et al. ${ }^{14}$ conducted a study among subjects working in the garments, carpets and weaving cotton industry. The authors identified that exposure to inhalable cotton dust was associated with significant reduction in "Forced Vital Capacity (FVC) and Forced Expiratory Volume in First Second (FEV1)". Similarly, Kahraman et al..$^{15}$ found that cotton dust exposure effected the lungs and reduces the FEV1 and FEV1/FVC ratio in cotton mill workers. These findings support the present study findings that exposure to cotton dust in any form decreases the pulmonary function.

Beshir et al. ${ }^{16}$ reported that exposure to cotton fibers and its associated dust in environments 
causes changes in the lung functions. A noticeable reduction was identified in Forced Vital Capacity and Forced Expiratory Volume in First Second" in the exposed group compared to the control. The ventilatory functions were positively correlated with the duration of exposure. ${ }^{16}$

Jing et al. ${ }^{17}$ reported that prolonged exposure to cotton fibers and its dust is allied with respiratory complaints and decline in FEV1. Moreover, it has also been demonstrated that subjects exposed to cotton fibers and its associated dust had larger and more frequent declines in FEV1 compared to silk exposed subjects. ${ }^{18}$ Similarly, the present study findings show that lung function test parameters, "Forced Vital Capacity; Forced Expiratory Flow-25\%; Forced Expiratory Flow50\%; Forced Expiratory Flow-75\%" among Hajj pilgrims who were wearing cotton towel ihrams were decreased compared to those who were wearing plain ihram.

Limitations of study: The study has some limitations, which relates to the small sample size. Hajj is the world's largest annual gathering where approximately 2.5 million pilgrims arrive from all over the world to perform Hajj, therefore, conducting research studies in such a mass gathering is not an easy task. The investigator led both groups separately from Riyadh to Makkah, Saudi Arabia. However, during Hajj at some point, both groups were sitting collectively and it was difficult to separate them. Moreover, in addition to cotton towel Ihram fibers, there were some confounding factors such as dust, mass gathering, close contact and viral infections during the Hajj period which may cause respiratory problems including lung function impairment.

\section{CONCLUSIONS}

Lung function parameters among Hajj pilgrims who were wearing cotton towel ihrams were decreased compared to those who were wearing plain ihram. The pattern of impairment of lung function shows obstructive peripheral airway lung involvement. However, one week after the removal of the Ihram, the lung function test parameters were reversed. It is advised to conduct further large sample size studies to confirm the present study observations to reach at better conclusions.

Acknowledgement: The authors are thankful to the "National Plan for Science and Technology and
Innovation (MAARIFAH), King Abdulaziz City for Science and Technology, Kingdom of Saudi Arabia for supporting the research project (Award \# 13 MED 1349-02)".

Conflict of Interests: The authors declare that they have no conflict of interest.

\section{REFERENCES}

1. Memish ZA, Stephens GM, Steffen R, Ahmed QA. Emergence of medicine for mass gatherings: lessons from the Hajj. Lancet Infect Dis. 2012;12:56-65. doi: 10.1016/ S1473-3099(11)70337-1.

2. Keman S, Jetten M, Douwes J, Borm PJ. Longitudinal changes in inflammatory markers in nasal lavage of cotton workers. Relation to endotoxin exposure and lung function changes. Int Arch Occup Environ Health. 1998;71:131-137.

3. Deris ZZ, Hasan H, Ab Wahab MS, Sulaiman SA, Naing $\mathrm{NN}$, Othman NH. The association between pre-morbid conditions and respiratory tract manifestations amongst Malaysian Hajj pilgrims. Trop Biomed. 2010;27:294-300.

4. Meo SA, Azeem MA, Ghori MG, Subhan MMF. Lung function and surface Electromyography of Intercostal muscles in cement mill workers. Int J Occup Med Environ Health. 2002;15:279-287.

5. Meo SA, Al-Drees AM, Al Masri AA, Al Rouq F, Azeem AM. Effect of Exposure Duration to Cement Dust on Respiratory Function of Non-Smoking Cement Mill Workers. Int J Environ Res Public Health. 2013;10:390-398. doi: 10.3390/ ijerph10010390.

6. Miller MR, Hankinson J, Brusasco V, Burgos F, Casaburi R, Coates A. Standardization of spirometry. Eur Respir J. 2005;26:319-338. doi: 10.1183/09031936.05.00034805.

7. Shafi S, Booy R, Haworth E, Rashid H, Memish ZA. Hajj: health lessons for mass gatherings. J Infect Public Health. 2008;1:27-32. doi: 10.1016/j.jiph.2008.08.008.

8. Shakir HA, Gazzaz ZJ, Dhaffar KO, Shahbaz J. Outpatient Services during (1423h) Hajj Season. Sultan Qaboos Uni Med J. 2006;6(1):47-50.

9. Simpson IJ, Aburizaiza OS, Siddique A, Barletta B, Blake NJ, Gartner A, et al. Air quality in Mecca and surrounding holy places in Saudi Arabia during Hajj: initial survey. Environ Sci Technol. 2014;48:8529-8537. doi: 10.1021 / es5017476.

10. Memish ZA. Health of the Hajj. Science. 2018;361(6402):533. doi: $10.1126 /$ science.aau9617.

11. Laumbach RJ, Kipen HM. Respiratory health effects of air pollution: update on biomass smoke and traffic pollution. J Allergy Clin Immunol. 2012;129:3-11. doi: 10.1016/j.jaci.2011.11.021.

12. Mohai P, Kweon BS, Lee S, Ard K. Air pollution around schools is linked to poorer student health and academic performance. Health Aff. 2011;30:852-862. doi: 10.1377/hlthaff.2011.0077.

13. Dangi BM, Bhise AR. Cotton dust exposure: Analysis of pulmonary function and respiratory symptoms. Lung India. 2017;34:144-149. doi: 10.4103/0970-2113.201319.

14. Paudyal P, Semple S, Gairhe SSteiner MF, Niven R, Ayres JG. Respiratory symptoms and cross-shift lung function in relation to cotton dust and endotoxin exposure in textile workers in Nepal: A crosssectional study. Occup Environ Med. 2015;72:870-876. doi: 10.1136/oemed-2014-102718. 
15. Kahraman H, Sucakli MH, Kilic T, Celik M, Koksal N, Ekerbicer HC. Longitudinal pulmonary functional loss in cotton textile workers: a 5-year follow-up study. Med Sci Monit. 2013;19:1176-1182. doi: 10.12659/ MSM.889681.

16. Beshir S, Mahdy-Abdallah H, Saad-Hussein A. Ventilatory functions in cotton textile workers and the role of some inflammatory cytokines. Toxicol Ind Health. 2013;29:114-120. doi: 10.1177/0748233711425071.

17. Jing $S$, Amar JM, Jing-qing $H$, Hongxi $Z$, Helian D, Li $S$. Chronic Lung Function Decline in Cotton Textile Workers: Roles of Historical and Recent Exposures to Endotoxin Environ Health Perspect. 2010;118:1620-1624. doi: 10.1289/ehp.0901178.

18. Wang X, Zhang HX, Sun BX, Dai HL, Hang JQ, Eisen $E$, et al. Cross-shift airway responses and longterm decline in FEV1 in cotton textile workers. Am J Respir Crit Care Med. 2008;177:316-320. doi: 10.1164/ rccm.200702-318OC.

\section{Authors' Contributions:}

SAM: Study design, supervised the project, data collection and manuscript writing.

MI: Data collection and manuscript writing.

AMU: Project management, data collection and analysis.

AAA and AHA: Support in travel to Makkah and data collection.

KAA: Data collection, Subjects recruitment and data collection.

All authors have approved the final version of the manuscript.
Authors:

1. Sultan Ayoub Meo,

Department of Physiology,

2. Muhammad Iqbal,

Department of Physiology,

3. Adnan Mahmood Usmani,

University Diabetes Centre,

4. Abdulrahman Abdulaziz Almana,

Department of Armed Forces Medical Services, King Fahad Armed Forces Hospital,

Jeddah, Saudi Arabia.

5. Abdulrahman Hamad Alrashed, Department of Family Medicine, King Faisal Specialist Hospital and Research Centre, Riyadh, Saudi Arabia.

6. Khalid Abdullah Al-Regaiey, Department of Physiology,

1-3,6: College of Medicine, King Saud University, Riyadh, Saudi Arabia. 